\title{
MANAGING SPECIAL EDUCATION STATEWIDE: DEVELOPING AN INTERDEPENDENT MANAGEMENT SYSTEM ${ }^{1}$
}

\author{
Leonard C. Burrello, Ed.D. \\ Indiana University \\ Nancy L. Kaye, Ph.D. \\ University of Wisconsin-Madison \\ Ronald E. Nutter, Ph.D. \\ University of Michigan
}

This article reports research on the development and evaluation of a statewide management network. A network of 529 persons nominated a peer task force which was determined to be highly representative of Michigan's 529 administrators and supervisors. This task force produced a series of products and procedures which the network of administrators and supervisors found both relevant and useful in their work. This research employed communication strategies appropriate to macrogroups to support the continued development of a Statewide Technical Assistance Network in Special Education (STANSE) - a model for state leadership personnel to use in producing state plans. It embodies public participation and annual reports to state governing boards, legislatures, and other significant publics.

\section{THE MANDATE TO PLAN}

Special educational administrators at each level in a state's educational system have increasingly been asked to describe and project more needs, programs, and expenditures for handicapped children and youth. While program planning is not new to administrators, the mandate to plan publicly within specific parameters is indeed a significant change from past management practices. Planning for the needs of the individual child, for the school building, for the school district, for the region, and even for the state department of education is a new path which will have to be traveled by administrators searching for alternatives.

The mandate to plan is both a legislative necessity (at most state levels and certainly at the federal level under P.L. 94-142) as well as an organizational

\footnotetext{
${ }^{1} \mathrm{~A}$ detailed description of the research design and results of this interorganizational planning model will be published separately by Nancy L. Kaye. It was deleted from this article because of the extensiveness of the data and because it demands special attention as a new application of communication methodology.
} 
necessity. In order to meet their management responsibility to plan, administrators at all levels will necessarily become dependent on one another for information to guide the direction and allocation of federal and state resources. This planning function serves as the administrator's public response, insuring the accountability of his efforts on behalf of all the handicapped. The research reported here describes the establishment and operation of a statewide planning forum to insure legislative compliance and administrative survival under state and federal mandates.

\section{NEED FOR STATE LEADERSHIP}

The need for state leadership in program planning in Michigan was substantiated during a long-range planning project reported by Gilliam and Burrello (1975) and Siantz and Burrello (1976). The results clearly suggested that the State's Special Education Service Area (SESA) needed to initiate leadership in statewide planning. Given this direction, the State Director of Special Education began to: (a) select a representative sample of administrators and supervisors to form a coordinated planning task force to create a statewide technical assistance network, (b) determine whether the task force was representative of all administrators and supervisors who composed the special education management network, (c) insure two-way communication between the selected representation and the other managers in the network, and (d) organize and establish priorities for useful and meaningful issues to meet the state's commitment to serve all handicapped from ages 0 to 25 .

\section{STATE TECHNICAL ASSISTANCE NETWORK IN SPECIAL EDUCATION (STANSE)}

Twenty-four managers, administrators, and program supervisors from intermediate units and LEAs were selected by the membership of their respective professional associations. They were then appointed by the State Director to a Statewide Management Task Force. Six additional at-large members were selected to give the Task Force complete demographic and geographical representation. Four state department staff members were also added by the State Director to give all management levels visibility as equal members of the network.

\section{VALIDATING THE REPRESENTATIVENESS OF THE TASK FORCE}

In order to ascertain the real as well as the apparent representativeness of the Task Force, the democratic nomination process was extensively analyzed. Evaluating the nomination process involved the use of two interrelated communication research strategies. The first strategy, designed to assess the communication channels of all members of the management network, is based on sociometric principles and is referred to as network analysis.

Each administrator and program supervisor was asked to determine the frequency and nature of his communication with every other person in the full management network of 529 persons. Three areas of communication were as- 
sessed: planning, change, and the person's job. They were to use a 4-month time frame from September to December 1975. Approximately 73\%, or 386 persons, of the entire network responded. Kaye's (1976) results showed that there were structured communication patterns in all three areas of planning, change, and job. Over 100 communication groups were linked by bridges (group members interacting with other group members) and liaisons (persons who did not meet group membership criteria but linked different communication groups). A total of 84 bridges and liaisons were identified from the three networks. These persons were identified as the key communicators in the system. STANSE membership accounted for a number of these key communicators; in fact, $78 \%$ of the Task Force members were identified as key communicators.

In summary, definable communication patterns emerged within the Michigan special education managerial system. The structure was seen to cover the state, but key communicators differed according to role. While members of STANSE contributed substantially to the linkages of groups, STANSE members differed from the rest of the network regarding communication roles. Key communicators, especially those in STANSE (including staff) and some SESA personnel, combined to provide the linkages necessary to communicate effectively with each other.

\section{DETERMINING THE RELATIONSHIP OF STANSE TO OTHER CONCEPTS}

Metric multidimensional scaling (the Galileo procedure) was used to determine the interrelationships between selected concepts. The Task Force and STANSE staff identified 16 concepts organized in a forced-choice format to insure that each concept was paired with every other one in order to assess the extent of the relationship of each concept to every other concept.
1. "My job"
2. STANSE
3. Management system
4. Child-centered
5. Efficient
6. State Special Education Serv- ices Area (SESA)
7. Planning
8. Frustrating
9. Change

10. Mainstreaming

11. Educational Planning and Placement Committee (EPPC)

12. P.L. 198 Michigan Mandatory Special Education Act

13. Parent Advisory Committee

14. Helpful

15. Labeling

16. Collective bargaining

The results of this analysis showed that the concept STANSE was relatively unknown to the subjects responding at time one, January 1976. This supported the assumption that STANSE is a concept with low mass, in that it is a new idea to the managers in special education. From the resulting interrelationships, message strategies were developed in order to move STANSE, as a concept, closer to the respondents' self-perceptions of their jobs. 
A dissemination plan was developed, utilizing information from network analysis and metric multidimensional scaling techniques. The key communicators would be the target audience for the messages, which would include association of STANSE with the concepts of Child-centered, Planning, and Helpful. At time two, June 1976, there was a change in the relative positions of the concepts "My job" and STANSE. The change was found to be statistically significant at the .01 level, using a difference of means test. The Task Force members themselves demonstrated the most units of change in their perception of the concepts STANSE and "My job." This was expected, since this group had worked with the concept of STANSE for 8 months.

Additional data were collected which confirmed the representativeness of STANSE members. A correlation was run on the Galileo data between STANSE members and the rest of the network, resulting in an $r$ of .82. Key communicators were also compared to the network in regards to range and diversity of attitudes; the correlation was .77 .

The significance of these findings lies in the fact that this pool of professional managers serves as an excellent barometer for the entire network. They provide an efficient and accurate representatation of the administrators and supervisors in the state. Planning with this representative sample to ascertain perceptions of managers on key issues is a necessary condition for moving in new directions, establishing action plans, and garnering political leverage to press for legal, program, or fiscal support. Probably most significant is the saving of human resources so as to make them available within any one state as a professional community of educators. The mutual pooling of all management resources maximizes existing human resources. Significant progress toward a statewide goal is already initiated because participation of significant others in the first stages of a planned change effort has begun.

STANSE was found to be a viable organizational innovation that should be continued because it appropriately reflected the needs of the state's asministrators and supervisors. It also promised to develop strategies to resolve identified problems.

\section{SETTING PRIORITIES FOR THE TASK FORCE}

In 3 months, meeting approximately 2 days per month, the Task Force explored the concept of STANSE, determined its manifest and latent agenda, and proceeded to identify 351 problems. These 351 problems were solicited both from the Task Force and the entire network. Through a problem definition and consensus testing process, these 351 problems were distilled down to 11 problem areas. Five problem areas were eventually selected by the Task Force after a ranking and weighing process developed by STANSE staff (Vernon \& Nutter, 1976). These problem areas were translated into goal statements based on their utility and likelihood of attainment by the end of the project year, August 1976. These goals were:

- to obtain consensus from the special education administrators and supervisors on a policy statement that would guide SESA in negotiations with other state agencies and service areas in the Department of Education 
- to provide field feedback to SESA regarding its reorganization and to determine the implications of that reorganization for intermediate and local school districts; to make recommendations for improving the interaction between state, intermediate, and local educational agencies

- to define the planning requirements of special education managers at the three levels

- to develop an information system for cooperative statewide planning

- to produce a state plan, which will describe both the service delivery system and the management system, and to design a planning process for developing the state plan to insure that relevant field input is provided

\section{ACCOMPLISHMENTS}

Between 1976 and 1977, the Task Force members and STANSE staff moved from planning to implementation, producing a number of specific products. More important, they have provided leadership in cooperative planning and management on key issues. Some of the STANSE products are:

1. A state planning framework - used in producing a state plan and guidelines for local and intermediate planning units based on individual education planning (see Figure 1).

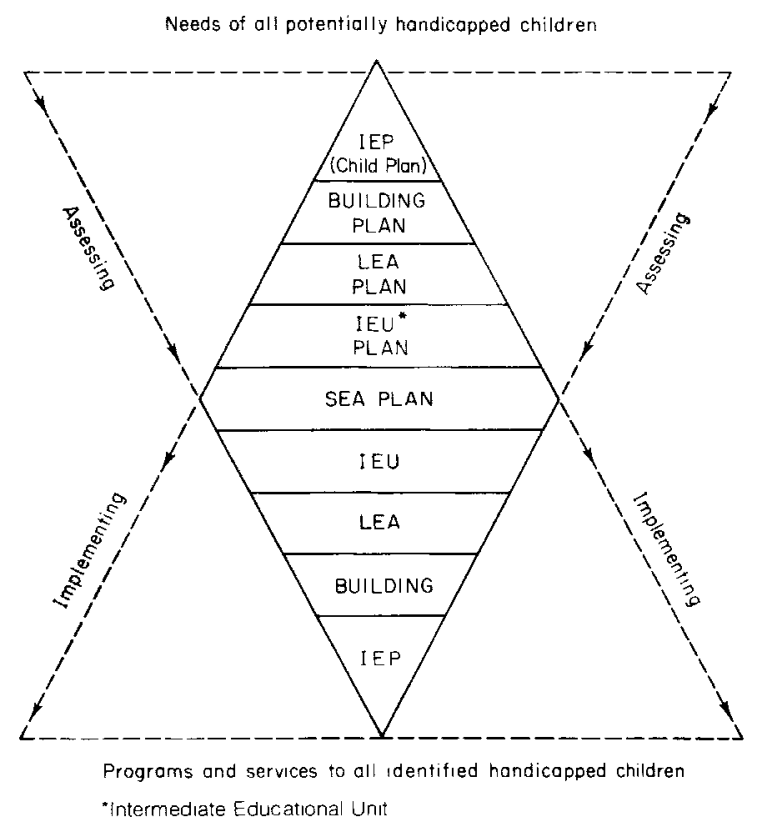

Figure 1. Role of state planning in the identification and delivery of services to handicapped children. (Reproduced from the Initial Report of the Statewide Technical Assistance Network in Special Education, Michigan State Department of Education, U.S. Office of Education, Bureau of Education for the Handicapped, 1975.) 
2. Planning schedules - used by state, intermediate, and local planners to determine federal and state requirements and deadlines under P.L. 94-142 and the state mandatory law.

3. A human resource system which identifies needs and provides peer consultation and training to individual school-community personnel.

4. A new organizational structure for the State Special Education Services Area.

5. A position paper on interagency responsibilities and relationships.

6. An interorganization planning structure - composed of the State Director, presidents of the administrator and supervisor associations, and the STANSE project director - to oversee and coordinate future statewide special education planning activities.

\section{IMPLICATIONS FOR STATE LEADERSHIP}

Increasing responsibilities to serve every child, uncertain fiscal resources, and public participation - all require special education administrators to assess how each will meet the challenges. The current climate suggests that special educators face a twofold challenge:

1. Redefinition of special education programs and personnel in their relationship to regular education administrative, instructional, and supportive personnel.

2. Negotiation of special education programs and services with public health, mental health, social services, and corrections - i.e., the entire human services system.

Developing positions and strategies for new forms of cooperation and negotiation with these two groups of professionals will affect state as well as local special education leadership personnel. The Michigan Department of Education today has both the perspective and momentum to initiate and coordinate its human resources so as to prepare a planned response for these challenges. Some of the following initiatives are now uniquely within the grasp of state leadership personnel: developing forums for planning, finding opportunities for shared leadership, and providing peer-based technical assistance and training which can utilize the rich field base of professional talent.

State departments are the designated agencies responsible for translating state and federal statutes into program and service standards which provide the parameters for local service delivery. The state plan required under Michigan rules and P.L. 94-142 is a management document which should outline the state's intended response within a targeted time frame with accountability specified. To be successfully implemented, the state plan must necessarily be a consensus document. Public participation and LEA input must be solicited and fed back before submission and implementation.

The process a state department uses to prepare and implement its plan could ultimately affect that plan's success or demise. The information necessary to its preparation flows from the individual educational planning process developed at the building level, transmitted to the district/county/or region, and ultimately to the state. As Figure 1 illustrates, the state plan is the fulcrum rather than the 
peak of a hierarchical pyramid where needs and programs are referred for action. The plan is a series of stipulated action steps designed to flow through the same process back through the intermediate unit, to the district, building, and to the individual child. The technology to handle and process the amount of data required is available and is being applied. This process inextricably ties planning, organization, and communication across the educational system's management levels into a common, shared bond.

Finally, the present political context continues to reinforce the need for maintaining a coalition of managers concerned with the needs of the handicapped child. As resources grow scarce and finite, a state leadership coalition must increase its rational planning, projecting, and strategic communication of needs to obtain commitments from legislators and others in the executive branch of government. The public participation explicitly stated in the statutes should be viewed as another extension of the special education professional community's past effort with parents and advocates. Both coalitions are necessary. Thus, political and rational planning strategies must be alternatively deployed in order to accomplish what we envision for the handicapped in the future.

\section{References}

Gilliam, J. E., \& Burrello, L. C. The futures: Long-range planning for special education. Part I, 1975, a statewide planning process. Michigan Department of Education and Bureau of Education for the Handicapped, Grant No. OEG-0-72-4309, U.S. Office of Education, 1975.

Kaye, N. Assessing communication patterns and attitudes of special education management personnel in technical assistance network. Doctoral dissertation, University of Michigan, Ann Arbor. University Microfilms, 1976.

Siantz, J. E., \& Burrello, L. C. The futures:
Long range planning for special education. Part II, 1976, a technical critique of one strategy. Student Research Project Grant No. OEG-G00-75-00361, U.S. Office of Education, 1976.

Vernon, D., \& Nutter, R. Formative evaluation of STANSE. In L. C. Burrello, N. Kaye, \& E. Peelle (Eds.), Statewide technical assistance network in special education: The initial report, 1975-76. Grant No. 0655-37, Michigan Department of Education and Grant No. OEG-007507294, U.S. Office of Education, 1976. 